\title{
MESA DE DEBATE: RETOS EN LA FORMACIÓN DEL PROFESORADO
}

\author{
Discussion board: Challenges in teacher education \\ Mesa de discussão: Desafios na formação de professores \\ María Dolores Alonso-Cortés Fradejas \\ Universidad de León, España. Teléfono: +34 987291125. Correo electrónico: \\ mdalof@unileon.es
}

\begin{abstract}
Resumen
Dado que uno de los objetivos de este X Congreso Internacional de Evaluación Formativa y Compartida es Inspirar, a partir del intercambio de conocimientos y experiencias, procesos de mejora docente en el profesorado, es preciso plantearse cuáles son los retos que tenemos que afrontar a la hora de planificar, diseñar y desarrollar la formación del profesorado. En la Mesa de Debate se discutirá sobre la cooperación entre los agentes que intervienen en dicha formación; sobre cómo esta debe dar respuesta a las demandas de los sistemas educativos; sobre la necesidad de hacer un seguimiento y evaluación de los programas formativos del profesorado y sobre la necesaria implicación, en ellos, de los docentes más cualificados.

Palabras clave: formación del profesorado
\end{abstract}

\begin{abstract}
Since one of the objectives of this 10th International Conference on Formative and Shared Assessment is to inspire, from the exchange of knowledge and experiences, processes of teacher improvement, it is necessary to consider what are the challenges that we have to face when it comes to planning, designing and developing teacher training. The discussion table will discuss on the cooperation between the agents involved in such training; on how it must respond to the demands of education systems; on the need to monitor and evaluate the training programs of teachers and on the necessary involvement of the most qualified teachers in them.
\end{abstract}

Keywords: teacher training 


\section{Resumo}

Dado que um dos objectivos do X Congresso Internacional de Avaliação Formativa e Partilhada é inspirar, a partir da troca de conhecimento e experiência, os processos de melhoria do ensino em professores, devem considerar quais os desafios que enfrentamos quando temos que planejar, projetar e desenvolver a formação dos professores. A mesa de discussão vai discutir a cooperação entre os atores envolvidos nesta formação; sobre como deve responder às exigências dos sistemas de educação; sobre a necessidade de acompanhamento e avaliação de programas de formação de professores e sobre o necessário envolvimento neles, os professores mais qualificados.

Palavras-chave: formação de professores

\section{Mesa redonda: Retos en la formación del profesorado}

Uno de los objetivos de este X Congreso Internacional de Evaluación Formativa y Compartida es Inspirar, a partir del intercambio de conocimientos y experiencias, procesos de mejora docente en el profesorado. Por ello, forma parte de su programa una Mesa de Debate en la que se va a discutir, en el mejor sentido de la palabra, sobre cuáles son los retos que tenemos que afrontar a la hora de planificar, diseñar y desarrollar la formación del profesorado.

Resulta obvio que cuando hablamos formación del profesorado no estamos pensando únicamente en la formación inicial, es decir, en la formación que se recibe en los Grados en Educación y en el Máster en Formación del Profesorado de Educación Secundaria y Bachillerato, Formación Profesional y Enseñanzas de Idiomas, sino también en la formación que reciben los docentes en activo y en la formación que se habría de recibir para un adecuado ingreso en la función docente, o sea, durante los primeros años de ejercicio profesional. Por tanto, quienes de una u otra manera participamos en la formación del profesorado deberíamos cooperar para ser capaces de elaborar un programa formativo coordinado y continuado. Sin embargo, no siempre es así. Las universidades y las administraciones públicas con competencias en este tema trabajan desconectadas y, en ocasiones, hasta de espaldas. Ese es el primer reto al que tendríamos que enfrentarnos.

Pregunta: ¿Es factible esta cooperación entre los responsables de los distintos niveles de formación del profesorado? ¿Cómo se podría trabajar de forma coordinada? 
Ese programa formativo debería incluir una serie de contenidos y procedimientos de actuación que permitan dar respuesta a las necesidades del sistema educativo. Actualmente, al menos en España, algunas de estas necesidades son las siguientes:

\section{Foco en el aprendizaje.}

Hasta hace unos años, los alumnos iban a los centros educativos a aprender y los docentes a enseñar. Como consecuencia del desarrollo del constructivismo, ahora los alumnos van a los centros educativos a aprender y los docentes han de ir a ayudarles a aprender. Ello supone perder protagonismo para cedérselo a los alumnos que son los que construyen su propio aprendizaje. Debemos formar docentes que sepan ir más allá de la mera instrucción y sepan cómo poner los andamios para que los aprendices puedan avanzar seguros. También tienen que saber actuar como modelos.

\section{Aprendizaje de procedimientos, estrategias y competencias}

Hasta no hace mucho, se consideraba que los alumnos debían aprender, fundamentalmente, conceptos. Con la implantación de la LOGSE, entraron a formar parte del currículo los procedimientos y las actitudes. Eso quiere decir que nuestros niños y jóvenes, deben saber pero también han de saber hacer y han de saber ser. Debemos formar docentes capaces de transmitir información pero también que sepan entrenar estrategias y desarrollar competencias.

\section{Aprendizaje Cooperativo y autorregulación}

Si en la mayoría de los contextos laborales solemos trabajar con otras personas para lograr resultados, no es lógico que, en las aulas, los aprendices realicen la mayor parte del trabajo en solitario. Además, es fundamental que aprendan a autorregularse. Debemos formar docentes que conciban el aprendizaje como un proceso de cooperación y como un proceso autorregulado. Han de estar preparados para controlar menos y ser tolerantes con los distintos ritmos y estilos de aprendizaje, conociendo distintas estrategias de actuación que lo garanticen.

\section{Prácticas docentes situacionales y tareas auténticas}

Hasta hace unos años, las aulas funcionaban como microcosmos. Ahora, los aprendizajes deben ponerse en relación con lo que sucede alrededor del alumnado. 
Hemos de formar docentes capaces de aprovechar las situaciones que emergen para proponer tareas auténticas que ayuden a los aprendices a ver la funcionalidad de lo que se trabaja en las aulas.

\section{Metodologías activas y participativas}

Las metodologías más adecuadas para poder afrontar todos estos retos son, sin duda, las denominadas metodologías activas. Tenemos que formar docentes que sepan ir más allá de la lección magistral y del libro de texto.

\section{Nuevas tecnologías}

En un mundo eminentemente tecnológico como el actual, los docentes han de saber utilizar las nuevas tecnologías como un recurso de enseñanza y aprendizaje. Han de saber sacar partido de las oportunidades de interacción que ofrecen y de las posibilidades de acceso a la información que permiten.

\section{Evaluación formativa, compartida y auténtica}

La necesidad más importante al que se enfrenta el sistema educativo actual es el de abordar adecuadamente la evaluación. Tenemos que formar docentes que sepan enfocar la evaluación como una actividad que genere aprendizaje. Se dice que se hace evaluación continua pero, en realidad, en muchos casos, se sigue haciendo una continua calificación. Y solo con una función: medir el rendimiento del alumnado, el cual, por otra parte, los docentes podrían determinar sin necesidad de exámenes y pruebas. No parece lógico invertir tanto tiempo en constatar lo ya sabido y que queden cosas por aprender. Es necesario modificar procedimientos de modo que la evaluación sea concebida como una oportunidad de mejorar.

Así pues, un segundo reto sería incluir en ese programa coordinado la formación necesaria para poder abordar estas demandas.

Pregunta: ¿Se están trabajando estos aspectos en los planes de estudio de los Grados en

Educación Infantil y en Educación Primaria y en el Máster en Formación de Profesorado? ¿Se están trabajando en los programas de formación permanente de las administraciones educativas? 
Por otro lado, para que la formación del profesorado produzca realmente efecto en el sistema educativo es preciso afrontar otro desafío: se deben establecer procedimientos de apoyo, seguimiento y evaluación. Hay que acompañar a los docentes que están dispuestos a aprender y a mejorar y hay que apoyarlos con mentores que durante algún tiempo les asesoren y supervisen. La formación permanente del profesorado tiene que estar estrechamente ligada a la implementación, en las aulas, de buenas prácticas que, una vez instauradas, retroalimenten la formación inicial y la formación de los docentes noveles. Asimismo, debe evaluarse su efectividad.

Pregunta: ¿Cómo se traduce en la programación de los centros educativos la formación permanente recibida por su profesorado mediante cursos promovidos por las administraciones públicas y/o universidades? ¿Cómo recibe la inspección las innovaciones derivadas de la formación permanente recibida por el profesorado? ¿Se hace algún tipo de seguimiento y evaluación?

Para todo ello, y este es el último y más importante de los retos sobre los que se debatirá, las universidades y las administraciones públicas con competencias en educación deben fomentar la participación, en los programas formativos, de los docentes en activo. Hemos de contar con su experiencia y con su saber: es imprescindible que sepamos implicarlos no solo como receptores de formación sino como formadores de otros docentes.

Pregunta: ¿Cuántos docentes en activo actúan como formadores?

\section{Referencias}

Darling-Hammond, L., \& Baratz-Snowden, J. (2007). A good teacher in every classroom: Preparing the highly qualified teachers our children deserve. Educational Horizons, 85(2), 111-132.

Pérez Gómez, A. I. (2010). Aprender a educar: nuevos desafíos para la formación de docentes. Revista interuniversitaria de formación del profesorado, (68), 37-60.

Imbernón Muñoz, F. (2006). Actualidad y nuevos retos de la formación permanente. Revista electrónica de investigación educativa, 8(2), 1-11. 